\title{
Selection of a new peptide homing SK-BR-3 breast cancer cells
}

\author{
Ana Cláudia Pereira ${ }^{1,2,3}$ (i) | Débora Ferreira ${ }^{1,2}$ (i) | Cátia Santos-Pereira, ${ }^{1,45}$ (D) | \\ Tatiana F. Vieira $^{4}$ (i) | Sérgio F. Sousa ${ }^{4}$ (i) | Goreti Sales $^{3}$ (i) $\mid$ Lígia R. Rodrigues ${ }^{1,2}$ (i)
}

${ }^{1} \mathrm{CEB}$ - Centre of Biological Engineering, University of Minho, Braga, Portugal

${ }^{2}$ MIT-Portugal Program, Lisbon, Portugal

${ }^{3}$ Biomark - Sensor Research, Superior Institute of Engineering of Porto, Porto, Portugal

${ }^{4}$ UCIBIO@REQUIMTE - BioSIM, Department of Biomedicine, Faculty of Medicine University of Porto, Alameda Professor Hernâni Monteiro, Porto, Portugal

${ }^{5} \mathrm{CBMA}$ - Centre of Molecular and Environmental Biology, Department of Biology, University of Minho, Braga, Portugal

\section{Correspondence}

Lígia R. Rodrigues, CEB - Centre of Biological Engineering, University of

Minho, Campus de Gualtar, 4710-057

Braga, Portugal.

Email: 1rmr@deb.uminho.pt

\section{Funding information}

European Regional Development

Fund; Fundação para a Ciência e a

Tecnologia, Grant/Award Number: UID/ BIO/04469/2020 and NORTE-01-0145-

FEDER-000004

\begin{abstract}
Breast cancer diagnosis remains a challenge, mostly due to its heterogeneity. This reality translates in delayed treatments, increasing treatment aggressiveness and lower chances of overall survival. The conventional detection techniques, although becoming increasingly sophisticated each year, still lack the ability to provide reliable conclusions without being time consuming, expensive, and uncomfortable for the patients. The identification of novel biomarkers for breast cancer research is therefore of utmost relevance for an early diagnosis. Moreover, breast cancer-specific peptide moieties can be used to develop novel targeted drug delivery systems. In this work, we used phage display to identify a novel peptide with specificity to the SK-BR-3 breast cancer cell line. Cytometry assays confirmed its specificity, while bioinformatics and docking studies predicted the potential biomarkers at the SK-BR-3 cells' surface. These findings can be potentially useful in the clinical context, contributing to more specific and targeted therapeutic solutions against HER2-positive breast cancer subtypes.
\end{abstract}

\section{K E Y W O R D S}

biomarker, breast cancer, CTGNQAAFC, phage display, SK-BR-3

\section{1 | INTRODUCTION}

Despite the advances in cancer research and the investments in sophisticated equipment, cancer is still responsible for almost one in every six deaths globally, according to the World Health Organization, with more than 14 million new cases every year and a projection of over 26 million by 2030 (Thun et al., 2010).

Among all types of cancer, breast cancer remains one of the most common causes of cancer-related death, with 1.7 million new cases annually, comprising $25 \%$ of all cancer

Ana Cláudia Pereira and Débora Ferreira contributed equally to this work as first authors types (Ghoncheh et al., 2016). Its heterogeneous nature occurs as a result of both intertumor and intratumor variations resulting in a decrease of detection and diagnosis accuracy, as well as of treatment effectiveness (Almendro \& Fuster, 2011; Song et al., 2016; Sørensen et al., 2017).

While the intertumor heterogeneity alone demands for personalized diagnosis and treatment, intratumor heterogeneity represents a tremendous challenge for treatment selection (Almendro \& Fuster, 2011; Song et al., 2016). For example, estrogen receptor (ER), progesterone receptor (PR), and human epidermal growth factor receptor-type 2 (HER2) expression varies in different regions within the same tumor, as well as the microenvironment components like stromal cells and extracellular matrix, causing resistance to therapies 
in some patients and, therefore, substantially affecting the effectiveness of the treatment (Almendro \& Fuster, 2011; Song et al., 2016).

Conventional detection techniques, like mammography, magnetic resonance imaging, and ultrasounds, as well as biopsies to detect ER, PR, and HER2 expression and molecular profiling with microarrays, have enabled the distinction between different breast cancer types (American Cancer Society, 2016; Le Du et al., 2013; Nobrega et al., 2016). Still, the diagnosis involves several invasive tests that demand time and cause patient discomfort in order to narrow down the chances of false positives and false negatives, and to accurately apply the most appropriate treatment (Hassan $\&$ El-Shenawee, 2011). Hence, finding new specific targeting moieties to diagnose each breast cancer subtype at early stages without the need of invasive tests remains an unmet need (Larimer \& Deutscher, 2014; Sauter, 2017).

The search for novel recognition elements has been, among other strategies, falling into the use of peptides since they can be easily synthesized and modified to improve stability, solubility, and tissue penetration (Silva et al., 2016). Peptides can be selected by evolutionary screening techniques, such as phage display. This in vitro methodology allows the identification of ligands for proteins and other macromolecules. Libraries of phage-displayed peptides are physically linked to their encoding nucleic acid (Bazan et al., 2012), allowing selection of binding partners through iterative and repeated cycles of in vitro panning and amplification, followed by DNA sequencing (Liu et al., 2016). Furthermore, phage display has the advantage of likely retaining the native structure and functional conformation of proteins without requiring any previous knowledge of the molecular composition at the site of interest, providing a rapid, simple, and economic identification of peptide ligands for various target molecules or structures $(\mathrm{Li}$ et al., 2017). In addition, peptides can be labeled with the appropriate moieties or conjugated with nanoparticles, liposomes, anti-cancer drugs for early imaging diagnosis and targeted therapy (Li et al., 2017; Nobrega et al., 2016). Although most phage display experiments suffer from amplification bias because it imparts unintended selection pressure beyond binding to the desired target, this disadvantage can be overcome through a simple method that uses a pRARE plasmid extracted from Rosetta cells and transformed into Escherichia coli cells. This decreases the chances of amplification bias, increasing the uniformity of phage production in a random library (Umlauf et al., 2015).

Herein, in this work, we identified a novel peptide, Pep1CTGNQAAFC, homing the HER2-positive breast cancer cell line SK-BR-3 using a commercial phage display library. The peptide herein identified was characterized for binding and selectivity. Bioinformatic tools were used to identify potential cell surface targets to which this peptide binds, envisaging their future application as a new targeting system for breast cancer diagnostic.

\section{2 | METHODS AND MATERIALS}

\subsection{Cell culture, media and buffers}

The human breast cancer cell line SK-BR-3 (ATCC HTB-30; provided by Dr. Ana Preto from the Centre of Molecular and Environmental Biology [CBMA-University of Minho]) and the BT-474 (ATCC HTB-20; provided by Dr. Amelia Silva from the University of Trás-os-Montes and Alto Douro) were grown in Dulbecco's Modified Eagle's Medium (DMEM, Biochrom) and DMEM:HAMs F-12, respectively, supplemented with $10 \%$ (v/v) fetal bovine serum (FBS, Biochrom) and $1 \%(\mathrm{v} / \mathrm{v})$ of penicillin-streptomycin (Biochrom). The human non-tumorigenic mammalian cell line MCF-10-2A (ATCC CRL-10781) obtained from ATCC was routinely cultivated in a 1:1 solution of DMEM:HAMs F-12 medium supplemented with 5\% horse serum (Merck Millipore), $20 \mathrm{ng} /$ $\mathrm{ml}$ epidermal growth factor (Merck Millipore), $100 \mathrm{ng} / \mathrm{ml}$ cholera toxin (Sigma-Aldrich), $0.01 \mathrm{mg} / \mathrm{ml}$ insulin (SigmaAldrich), $500 \mathrm{ng} / \mathrm{ml}$ hydrocortisone, 95\% (Sigma-Aldrich) and $1 \%$ penicillin-streptomycin. Cells were maintained at $37^{\circ} \mathrm{C}$ with $5 \% \mathrm{CO}_{2}$. Sub-culturing was performed when the cell culture reached $80 \%$ of confluence. The cells were washed using phosphate-buffered saline 1× pH 7.4 (PBS 1×:137 mM $\mathrm{NaCl}$ [Nzytech], $2.7 \mathrm{mM} \mathrm{KCl}$ [ChemLab], 10 mM Na${ }_{2} \mathrm{HPO}_{4}$ [Scharlau] and $2 \mathrm{mM} \mathrm{KH}_{2} \mathrm{PO}_{4}$ [Panreac]) and detached using Trypsin/EDTA solution [Biochrom].

\section{2 | In vitro biopanning methodology}

A commercial phage display library, Ph.D. ${ }^{\text {TM }}-\mathrm{C} 7 \mathrm{C}$ library purchased from New England BioLabs (NEB), was used. The library consists of $1.2 \times 10^{9}$ electroporated sequences and a concentration of $1 \times 10^{13}$ plaque-forming units per milliliter (PFUs/ml). An adaptation of a biopanning protocol described by Giordano et al. (2001) using SKBR-3 cell line as target was followed as stated elsewhere (Nobrega et al., 2016; Silva et al., 2016). This procedure was repeated for a total of four rounds of panning. A final counter-selection step was included using the non-tumorigenic MCF-10-2A cell line. Due to titer losses, the phage pool was amplified in the last two rounds using a modified E. coli JM109 ${ }^{+}$strain (Silva et al., 2016) which has a plasmid (pRARE) that encodes for six low abundance tRNAs, reducing the amplification bias (Umlauf et al., 2015). The phage titer was determined for each round of selection using the double layer agar technique in LB plates $(25 \mathrm{~g} / \mathrm{L}$ Luria Bertani broth [Nzytech] with $20 \mathrm{~g} / \mathrm{L}$ agar [VWR]) 
supplemented with $0.25 \mathrm{mM}$ IPTG (Nzytech) and $0.05 \mathrm{~g} / \mathrm{L}$ $\mathrm{X}$-gal (Nzytech). The number of transducing units was calculated by counting the blue plaques after overnight incubation at $37^{\circ} \mathrm{C}$.

\subsection{Selection and amplification of positive clones}

The ssDNA of individual clones was extracted using a standard protocol (NEB:Ph.D.TM). Briefly, the iodide buffer $(10 \mathrm{mM}$ Tris- $\mathrm{HCl}, 1 \mathrm{mM}$ EDTA, and $4 \mathrm{M}$ NaI [SigmaAldrich], $\mathrm{pH}$ 8.0) and ethanol were used to precipitate the DNA. The final pellets were resuspended in $30 \mu \mathrm{l}$ of TE buffer (10 mM Tris-HCl, $1 \mathrm{mM}$ EDTA, $\mathrm{pH}$ 8.0), quantified by Nanodrop 1000, and confirmed by electrophoresis in TAE $1 \times$ buffer in a $2 \%$ gel at $90 \mathrm{~V}$ for $50 \mathrm{~min}$.

The amplification of each selected clone was carried out by PCR using 5'- TTAACTCCCTGCAAGCCTCA-3' as the forward primer and 5'- CCCTCATAGTTAGCGTAACG -3' as the reverse primer. The PCRs were prepared using the MasterMixS from peqGOLD and $10 \mathrm{ng}$ of phage DNA in a $20 \mu \mathrm{l}$ reaction final volume, with the following conditions: 35 cycles of $30 \mathrm{~s}$ of denaturation at $95^{\circ} \mathrm{C}, 30 \mathrm{~s}$ of annealing at $60.5^{\circ} \mathrm{C}$ and $1 \mathrm{~min}$ of extension at $72^{\circ} \mathrm{C}$. The amplifications were then confirmed by electrophoresis in TAE $1 \times$ buffer in a $2 \%$ gel at $90 \mathrm{~V}$ for $50 \mathrm{~min}$.

\subsection{DNA sequencing and insert analysis}

The DNA products obtained from amplification were prepared for sequencing using Illustra ExoProStar. Sequencing was carried out by GATC Biotech with the forward primer 5' - TTAACTCCCTGCAAGCCTCA -3'. Vector NTI (Vector NTI Advance, version 11.5, Invitrogen) was used to analyze the correct insertion of the peptides, taking into consideration that the displayed peptides should be expressed at the N-terminus of pIII, followed by the Gly-Gly-Gly-Ser spacer and wild-type pIII sequence.

\section{5 | Binding assays}

Bacteriophage labeling was carried out as previously described (Silva et al., 2016). Briefly, around $1 \times 10^{10}$ PFUs/ $\mathrm{ml}$ of phage suspension were precipitated with $20 \%$ polyethylene glycol (PEG) 8,000/2.5 M NaCl and resuspended in $0.1 \mathrm{M} \mathrm{NaHCO}_{3} \mathrm{pH} 8.5$ (Sigma) and then incubated with Alexa Fluor 488 tetrafluorophenyl ester (Alfagene), previously dissolved in anhydrous DMSO. After incubation, the labeled phages were recovered by centrifugation at 7,500 g for $5 \mathrm{~min}$ at $4^{\circ} \mathrm{C}$ using amicon- 15 centrifugal filter units with a nominal molecular weight limit of $50 \mathrm{kDa}$ (Merck). Final upper solution was resupended in $1 \mathrm{ml}$ of PBS.

Binding assays were characterized based on selectivity and specificity of the phages against the target cell line, SKBR-3, as well as BT-474 and MCF-10-2A cell lines, through cytometry. Briefly, $1 \times 10^{5}$ cells were washed with PBS $1 \times$ and blocked with a $3 \%$ BSA solution in PBS $1 \times$ for $1 \mathrm{hr}$ at $4^{\circ} \mathrm{C}$. Afterward, the cells were washed with PBS $1 \times$ with Tween-20 (PBST, PBS $1 \times$ with $0.1 \%$ (v/v) Tween 20) and incubated with the labeled phages for $1 \mathrm{hr}$ at $4^{\circ} \mathrm{C}$. The cells were then washed with PBST and suspended in PBS $1 \times$ for cytometry analysis with the $\mathrm{EC} 800^{\mathrm{TM}}$ flow cytometer analyzer (Sony Biotechnology), where a total of 15,000 events were accounted.

\section{6 | Peptide analysis and docking studies}

The identified peptide sequences were scanned using the Scanner and Reporter of Target-Unrelated Peptides (SAROTUP) webserver in order to accurately remove the existence of target-unrelated peptides, false positives, and existing mimotopes (Huang et al., 2010). Then, the sequences were analyzed through the Basic Local Alignment Search Tool (BLAST) algorithm for homology to proteins with known correlation with cancer and, for this purpose, the BLAST search program was used against Homo sapiens protein database. For the docking studies, a list of SK-BR-3 biomarkers and cell receptors were retrieved from literature (Mota et al., 2017) and the Harmonizome database (Rouillard et al., 2016), using "cytoplasmic membrane protein," "cell receptor" and "breast cancer biomarker" as keywords, in order to select potential cell surface targets for the sequences obtained. The receptors and membrane proteins expressed at the SK-BR-3 cell's cytoplasmic membrane were listed taking into account their high or low expression levels (data not shown).

A total of 60 candidates were collected and, afterward, a literature search was performed for each of them to select only those expressed at the cell surface. This was the starting point criterion, since all assays were conducted at $4{ }^{\circ} \mathrm{C}$ and, therefore, no phage internalization was expected. Out of the 60,30 candidates satisfied the criterion, according to Uniprot database, and are shown in Table S1. These 30 candidates were then used for the subsequent studies, where each of the proteins was prepared for protein-ligand docking (Sousa et al., 2006, 2013), considering a flexible peptide. Protein structures were searched in the Protein Data Bank (https:// www.rcsb.org/) (Berman et al., 2000). When more than one structure was available for a particular human protein, the selection of the structures to be used was based on some fundamental aspects: priority to structures with good resolution (bellow $2 \AA$ ), absence of mutated residues, and presence of a 
crystallographic ligand, to be used as reference for a putative binding pocket. However, it was not always possible to choose a structure with all these characteristics. Of the 30 possible protein targets, only 17 had PDB structures (Table S2). For the remaining 13 human proteins, a model was retrieved from the SWISS-MODEL Repository (Table S3), a database of annotated 3D protein structure models generated by the SWISS-MODEL homology-modeling pipeline (Bienert et al., 2017), which has been shown to produce models with good accuracy in comparison with the corresponding experimentally determined structures (Waterhouse et al., 2018). It currently holds over 400,000 high-quality models covering almost $20 \%$ of Swiss-Prot/UniProtKB entries. For each protein, structural models were chosen taking into account the Global Model Quality Estimation (GMQE) and QMEAN (Studer et al., 2020) scores. The first considers the template search method and the alignment between the target and the template while the latter generates both per residue and global quality estimates based on statistical potentials of mean force (Studer et al., 2020; Waterhouse et al., 2018) (Table S2).

The structure of Pep1 was created in ChemDraw 19.0 and converted from SMILE format with OpenBabel (O'Boyle et al., 2011). Partial charges and hydrogen atoms were added according to the protonation at physiological $\mathrm{pH}$ and the initial 3D structure was generated and optimized.

Docking was performed with two independent proteinligand docking programs considering a flexible peptide: GOLD (ChemPLP scoring function) (Jones et al., 1997) and AutoDock Vina (Trott \& Olson, 2010). The reasoning behind the choice of two docking alternatives was to evaluate consistency and cross-validate results. They are widely used tools to predict protein-ligand interactions (Sousa et al., 2006, 2013), as well as protein-peptide interactions, as recently reviewed (Hauser \& Windshügel, 2016).

For both programs, initial coordinates for the putative binding pocket for each possible target were preferentially defined based on known co-crystallized ligands. When there was no information about the exact location of a binding pocket, Fpocket (Le Guilloux et al., 2009), a software for ligand pocket detection and characterization was used to predict it. The pockets predicted were then analyzed and a selection based on pocket score and Solvent Accessible Surface Area was performed. Fpocket has been extensively used for binding pocket detection in a variety of targets and has shown very good results (Gervasoni et al., 2020; Schmidtke \& Barril, 2010; Schmidtke et al., 2010). Re-docking was employed as a validation tool to evaluate the protocols' ability in reproducing the orientation and geometry of the co-crystallized ligands.

The peptide was docked into the structures of all the possible protein targets with GOLD (ChemPLP) and AutoDock Vina. Docking conditions for GOLD (ChemPLP) were binding pocket radius of $15 \AA$, search efficiency of $150 \%$ and the number of runs was set to 100 . For Vina, the grid box was set to $30 \AA$ in all dimensions $(x, y, z)$ and the exhaustiveness of the search was set to 100 . These conditions are more extreme than those typically used in standard protein-ligand docking protocols (Hauser \& Windshügel, 2016; Vieira \& Sousa, 2019), but were chosen to ensure a greater exploration of the conformational space of the protein-peptide association and a higher accuracy in the predictions. Consistency in the docking protocol for each software is important to have confidence and compare the results. Ranked lists of the most likely protein targets were obtained with each program. Finally, GOLD (ChemPLP) and Vina scoring values were normalized and compared and a final ranked list was prepared. The predicted protein-peptide conformations were visually inspected and analyzed.

\section{7 | Statistical analysis}

The statistical analysis was performed using GraphPad Prism 5.03 (GraphPad Software, Inc.). Statistical significance was evaluated using one-way ANOVA with Tukey's multiple comparison test, with a 95\% significance level.

\section{3 | RESULTS AND DISCUSSION}

\section{1 | Biopanning identified two peptides binding to SK-BR-3 cells}

Phage display has been extensively used in the cancer research field (Aghebati-Maleki et al., 2016; Bakhshinejad et al., 2015; Bazan et al., 2012; Ferreira et al., 2019; Nobrega et al., 2016; Shukla \& Krag, 2005; Sørensen et al., 2017). It allows, among others, the use of whole cells as targets against a wide range of peptides, without the need of previous knowledge of the cells' membrane biochemical composition.

In order to isolate specific peptides for the SK-BR-3 cell line, the Ph.D. ${ }^{\mathrm{TM}}$ - C7C library commercial library was used. The biopanning consisted of four rounds for phage pool enrichment followed by a counter-selection round with control cell line MCF-10-2A. The output (number of recovered plaque-forming phages) divided by the input (number of plaque-forming phages from the previous selection round) infers the phage binding efficiency after each round. Due to titer losses, amplification of the phage pool was conducted after round 3 and 4, resulting in a higher input titer (Figure 1). These results strongly suggest an enrichment between rounds.

After the counter-selection round, several random individual clones were isolated, amplified by PCR and selected for DNA sequencing, showing two different variant sequences, Pep1-CTGNQAAFC and Pep2-CTSLFMNDC, with a hit 


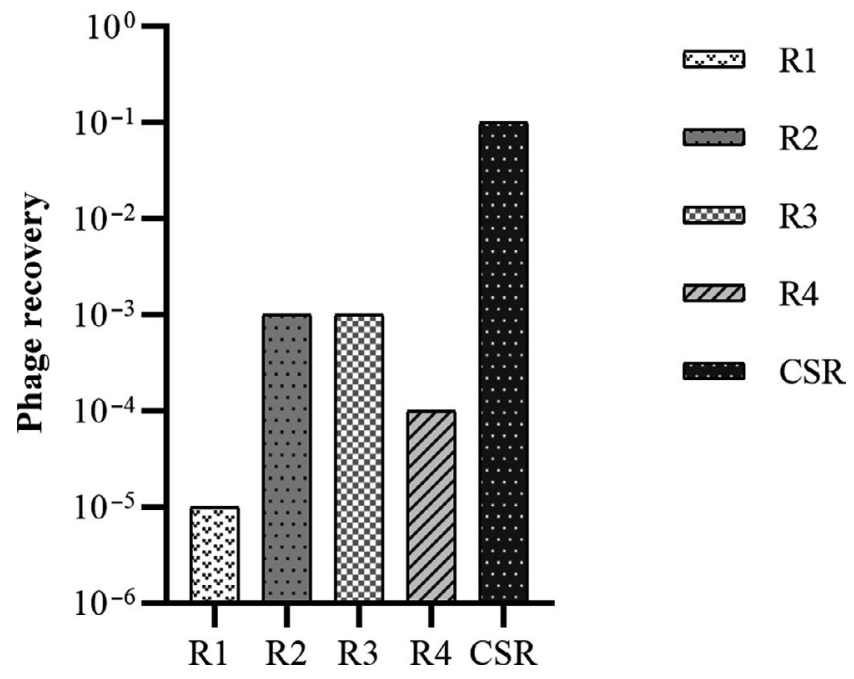

F I G URE 1 Phage binding efficiency and phage recovery after in vitro biopanning using a disulfide-constrained peptide library against SK-BR-3 cells. (a) Enrichment of binding phages for each biopanning round and (b) Phage recovery, calculated as the ratio between output and input of each biopanning round histogram of SK-BR-3 cells, for both Pep1 and Pep2, but not for other two cell lines (data not shown).

Statistical analysis of the data was performed. Results presented in Figure 2 were obtained after subtraction of cells' autofluorescence and confirm a high specificity between SK-BR-3 cells and both Pep1-CTGNQAAFC and Pep2-CTSLFMNDC, with $p<.0001$. This statistical significance was not observed for MCF-10-2A nor BT-474 cells. Moreover, when comparing fluorescence signal between the different cell lines for the same peptide, SK-BR-3 cells showed an increased signal with statistical significance as compared to MCF-10-2A $(p<.001)$ and BT-474 $(p<.0001)$ for Pep1. This statistical significance was not observed for Pep2 and therefore, the following experiments were conducted only with Pep1.

As no binding to cell line BT-474 was observed, we suspect that the HER2 receptor might not be the target of the Pep1, since both cell lines, BT-474 and SK-BR-3, overexpress this receptor and data analysis only showed statistical significance for Pep1 toward the latter one.

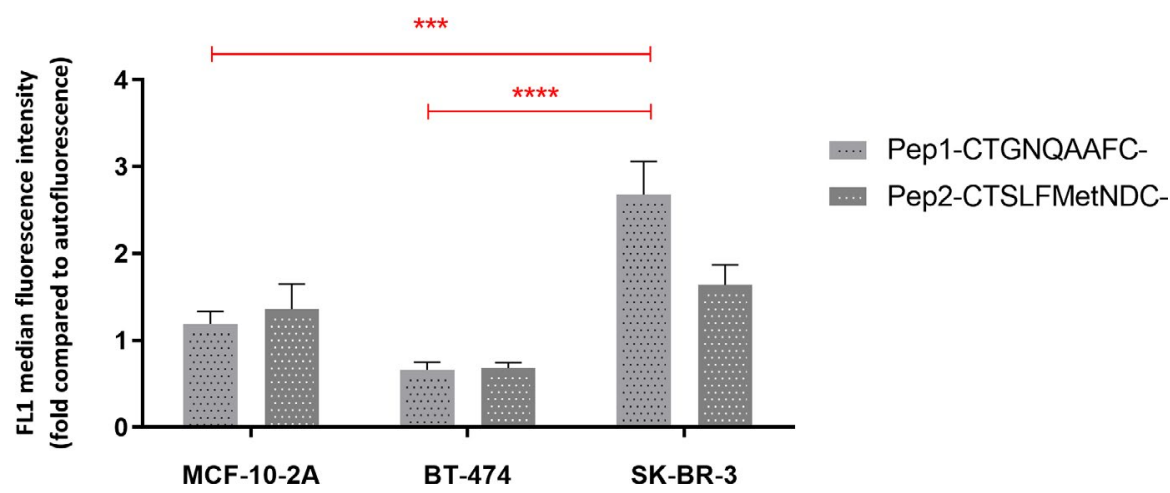

F I G U RE 2 Binding ability of Pep1 and Pep2 toward the breast cell lines MCF-10-2A, BT-474 and SK-BR-3 demonstrated by flow cytometry. Peptide 1 (Pep1) relates to the variant CTGNQAAFC and peptide 2 (Pep2) relates to the variant CTSLFMNDC. This data is expressed as the mean $\pm S D$ of three independent experiments. Two-way ANOVA indicates statistically significant differences within the group assessed by Tukey post-test and denoted as follows: ****p $<.0001$, ***p $p .001$ and ns $p>.05$ [Colour figure can be viewed at wileyonlinelibrary.com]

of $75 \%$ for Pep1 and $25 \%$ for Pep2. Moreover, these two sequences were aligned for the identification of small motif sequences and only threonine $(\mathrm{T})$ appeared repeated in the second position in both peptides.

\section{2 | Binding assays confirm affinity and specificity of Pept 1 for SK-BR-3 cells}

Phages expressing Pep1-CTGNQAAFC and Pep2CTSLFMNDC were used in binding assays, with MCF10-2A cells serving as a negative control and BT-474 cells to test the peptides' specificity toward the HER2 receptor. We observed a significant fluorescence curve shift in the

\subsection{C5AR1 and CX3CR1 are potential targets of Pept 1}

From this point on, only the Pep1 sequence was used for bioinformatics analysis and docking studies. First, the sequence was analyzed through the SAROTUP (Huang et al., 2010) webserver that is the most extensive database for assessing peptides derived from phage display protocols, in order to remove the existence of false positives and target-unrelated peptides (TUPs). The software predicted that the identified peptide does not bind to contaminants or other items of the selection process, and also that it is a clone without a growth propagation advantage, being more likely a true binder with high affinity to the target. Moreover, the results also showed 
that this sequence does not bear any known TUP motifs and no identical peptides in the Biopanning Data Bank (BDB) database were found, thus highlighting the novelty of the peptide herein selected. To determine its homology with previous known cancer-related proteins, the protein-protein BLAST analysis was performed and no significant similarities were found.

Docking results are reported in Table S4. A good consistency of the ranked predictions of GOLD and Vina was obtained. After normalizing and comparing the docking scores obtained with GOLD (ChemPLP) and Vina, and carefully analyzing the binding poses, a selection of the 6 most likely protein targets able to interact with Pep1, was made. These results are gathered in Table 1, together with the scores for ERBB2 (HER2) for comparative purposes.

The ChemPLP scoring function in GOLD uses Piecewise Linear Potential to treat van der Waals and repulsive terms. It is designed to predict the ligand binding pose rather than its binding affinity. It is a dimensionless fitness score, and its interpretation is the higher the score, the better the binding affinity (Verdonk et al., 2003). AutoDock Vina, on the other hand, is a mixed empirical and knowledge-based scoring function that divides the binding free energy into several terms that describe the protein-ligand interactions and used structural information obtained experimentally. It scores the poses in a metric that approximates binding free energy predictions, that is, the more negative the stronger the binding affinity (Trott \& Olson, 2010).

Overall, the results presented indicate good consistency between the two docking programs. Both ChemPLP and Vina yielded high scores to Complement component 5a receptor 1 (C5AR1) and Chemokine (C-X3-C motif) receptor 1 (CX3CR1). Also, there seems to be a clear prevalence of

TA B LE 1 List of the six proteins that presented the highest binding score with Pep1, along with ERBB2 scores, for both docking programs and main interacting residues

\begin{tabular}{|c|c|c|c|}
\hline C5AR1 & 73.80 & -8.4 & $\begin{array}{l}\text { E27, Y278, K365, } \\
\text { P356 }\end{array}$ \\
\hline CX3CR1 & 66.66 & -9.0 & $\begin{array}{l}\text { Y90, Q164, } \\
\text { G177, Y179, } \\
\text { R191 }\end{array}$ \\
\hline INSR & 64.80 & -8.3 & $\begin{array}{l}\text { R1000, R1026, } \\
\text { A1080, N1097 }\end{array}$ \\
\hline $\mathrm{OR} 2 \mathrm{H} 2$ & 60.91 & -8.6 & N82, C177, K270 \\
\hline GPR62 & 68.11 & -7.1 & $\begin{array}{l}\text { P207, R231, } \\
\text { R233, G237 }\end{array}$ \\
\hline GPR143 & 62.77 & -7.6 & A61, S67 \\
\hline ERBB2 & 64.01 & -4.2 & $\begin{array}{c}\text { S728, G729, } \\
\text { F731, T733, } \\
\text { R756, D808 }\end{array}$ \\
\hline
\end{tabular}

$\mathrm{G}$ protein-coupled receptor proteins among the top results. Interestingly, HER2 receptor low scores corroborated the hypothesis that this receptor might not be the Pep1 target.

The C5AR1 and CX3CR1, along with Olfactory receptor, family 2 , subfamily $\mathrm{H}$, member 2 (OR2H2), G protein-coupled receptor 62 (GPR62) and G protein-coupled receptor 143 (GPR143) are five of the top six scored receptors and all belong to the $\mathrm{G}$ protein-coupled receptors.

The G protein-coupled family (GPCR) comprise a class of proteins that contribute directly in many physiological responses and have great potential as therapeutic targets for a wide range of diseases (Rosenbaum et al., 2009). At a cellular level, these proteins regulate cell proliferation, as well as cell survival and motility, and have been emerging as indubitably key players in tumor growth, angiogenesis and metastasis (Bar-Shavit et al., 2016; Lappano \& Maggiolini, 2012). Moreover, these receptors are the most targeted gene family for FDA-approved drugs (Sriram et al., 2019).

C5AR1 has been found in tumor cells of several cancers. Patients with positive or high expression in lung, breast, kidney and gastric cancer showed lower survival rate than that of patients with negative expression (Yuxuan, 2019). An abnormal expression of this receptor has been associated with activation of downstream pathways with beneficial processes that promotes tumor progression and metastasis (Yuxuan, 2019). In relation to breast cancer, the correlation between C5AR1 expression in cancer cells and the tumor development suggests this receptor might be closely associated with breast cancer progression and even could be considered as a new target, in particular to triple-negative breast cancer (TNBC), despite not being considered a specific biomarker (Imamura et al., 2016). On a similar note, CX3CR1 is widely associated with several types of cancers, including breast cancer, pancreatic cancer, gastric cancer, and colorectal cancer (Erreni et al., 2016; Singh, 2010; Wang et al., 2017; Wei et al., 2015). It has been shown to play a significant role in cancer metastasis, promoting tumor proliferation and migration, demonstrating both the biological and clinical significance of this receptor in breast cancer aggressiveness (Singh, 2010). Moreover, it has been suggested that CX3CR1 could be used as a diagnostic biomarker for pancreatic cancer (Wang et al., 2017).

The Isoform short of Insulin Receptor (INSR), which is an isoform that can be activated by insulin and insulin growth factors 1 and 2, belongs to the receptor tyrosine kinase family of proteins, being the encoded insulin receptor preproprotein processed to produce alpha and beta subunits to form a heterotetrameric receptor (Boucher et al., 2014). The insulin signaling pathway is activated through binding of insulin or other ligands to this receptor, which regulates glucose uptake and release, as well as the synthesis and storage of lipids, carbohydrates and proteins (Boucher et al., 2014). Insulin receptor's functions in breast cancer biology have 
been well-documented (Vigneri et al., 2016), being its content approximately $80 \%$ higher in breast cancer tissues when compared to normal breast ones (Papa et al., 1990).

$\mathrm{OR} 2 \mathrm{H} 2$ is a membrane olfactory receptor that interacts with odorant molecules in the nose to initiate a neuronal response that triggers the perception of a smell (Lee et al., 2019). This receptor is also expressed in diverse extra-nasal tissues and is involved in several different biological functions. Recently, rather than be only highly specialized components of the olfactory sub-genome, these type of receptors are now considered candidate cancer genes, being associated with breast cancer (Ranzani et al., 2017; Weber et al., 2018).

GPR62 was first identified by Lee et al. (2001) and its mRNA expression was detected in the basal forebrain, frontal cortex, caudate, putamen, thalamus, and hippocampus. Given its high expression in brain tissues, it is hypothesized that its ligand may be a neurotransmitter (Lee et al., 2001). The GPR143 encodes a protein necessary to control the growth of melanossomes (Bassi et al., 1995; Schiaffino et al., 1999) and in 102 cases of melanoma it was found an enrichment of its gene product. It is also a favorable prognostic marker in renal and cervical cancer (Uhlen et al., 2010).

Pep1, due to its loop conformation, is very bulky, as such, the binding pocket (represented in yellow surface) of the possible protein target must be big enough to allow interaction. In
Figure 3, the interaction of the Pep1 with the top 6 potential protein candidates is presented in detail. The peptide-protein interactions are mainly due to hydrogen bonding between the peptide and protein side chains.

C5AR1 presents the highest ChemPLP score and second highest Vina score. Pep1 interacts, via salt bridge, with Lys365, this is a strong interaction and highly contributes to the stability of Pep1 in the binding pocket. The $\mathrm{NH}_{2}$ groups of Pep1 present weak interactions with the side chains of two amino acid residues Glu27 and Pro356. Finally, the NH group of Tyr278 formed a weak H-bond interaction with Pep1. CX3CR1 was the target that presented the highest score for Vina and third highest for ChemPLP. Pep1 seems to be buried in the active site. There is the formation of a weak hydrogen bond between Pep1 and the NH group of Gln164. Gly177 and Arg191 form H-bonds with the $\mathrm{NH}_{2}$ groups of Pep1. Oxygen atoms from Tyr90 and Tyr179 side chains show weak H-bond interactions with the oxygen groups of the peptide. INSR seems to present a pocket that is shallower and closer to the surface of the protein. Pep1 interacts via salt bridge with the guanidinium $\left(\left(\mathrm{NH}_{2}\right)_{2}{ }^{+}\right)$group of $\mathrm{Arg} 1000$ and $\mathrm{Arg} 1026$. It also forms H-bonds with Ala1080 and Asn1097. Pep1 interacts with three amino acid residues of OR2H2. Lys270 forms salt bridges and H-bonds with Pep1, suggesting that this residue may contribute significantly to the Pep1 stability.
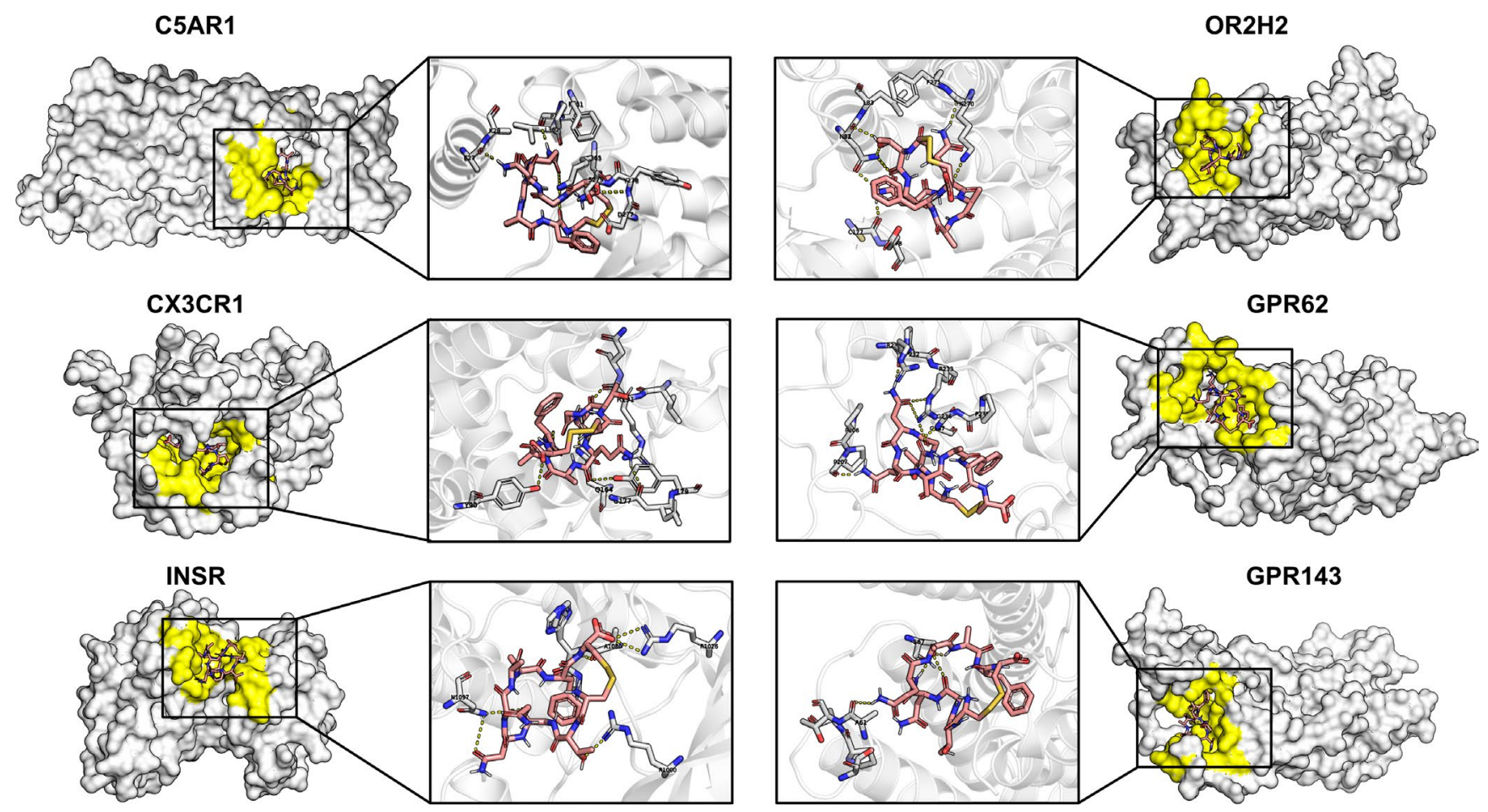

F I G URE 3 Representation of the binding pocket of the top 6 peptide-docking solutions. Proteins are presented in surface with the active site highlighted in yellow. Pep1 is shown in sticks, with carbon atom represented in pink, red for oxygen atom and blue for nitrogen atom. In the detailed images, the protein is shown in cartoon and the interacting amino acid residues are displayed in sticks with white carbons, red oxygen, and blue nitrogen atoms. The yellow dot lines represent the electrostatic interactions between the peptide and the amino acid residues [Colour figure can be viewed at wileyonlinelibrary.com] 
Additionally, Asn82 forms multiple weak hydrogen bonds between its side chain and Pep1 and one of its $\mathrm{NH}_{2}$ group forms a hydrogen bond with Cys177. GPR62 interacts with the $\mathrm{NH}_{2}$ group of Pep1 by forming H-bonds with Pro207, $\operatorname{Arg} 231$, and Gly237. There is also the formation of a salt bridge between Pep1 and the Arg233 residue. Interaction of Pep1 with GPR143, on the other hand, is mainly due to weak H-bond with Ala61 and Ser67. This might be explained by the fact that GPR143's pocket is shallower than the binding pocket of GPR62.

These results support our experimental data since neither MCF-10-2A nor BT-474 cell lines express these receptors or biomarkers, suggesting that at least one of these proteins could have a potential role as a targeting receptor for Pep1. The docking results guided the selection from 30 to six possible proteins. The next step would be to experimentally validate the binding of Pep1 to these specific proteins. Finding such targets is important given the current state of breast cancer diagnosis. Developing approaches that simultaneously allow an accurate early detection with minimum discomfort for the patient is urgent and many efforts have been made to introduce the detection of circulating tumor cells as a standardized practice, with several studies suggesting different ideas for different breast cancer targets (Frithiof et al., 2015; Gilbey et al., 2004; Kruspe et al., 2017; Loeian et al., 2019). This is an important step that, once in a clinical context, could help identify patients at higher risk of developing metastasis in early stages, thus allowing oncologists to determine with a better accuracy the necessary aggressive treatment and, simultaneously, sparing low-risk patients from unnecessary therapies and all the side effects that come with them.

\section{4 | CONCLUSION}

Current recognition elements lack the necessary specificity to accurately diagnose breast cancer subtypes without invasive procedures. Some of the main limitations include having to own previous knowledge of the cell's biochemical architecture, presenting variations at their surface, and often camouflaging the target. Furthermore, the cell's targets are often isolated for experimental assays, introducing the possibility of a different structural conformation hence making the potential biomarker non-functional in its purpose. Therefore, searching for candidates that can target whole cells might be a way to narrow down these limitations.

In this work, we identified a novel peptide with specificity to the SK-BR-3 breast cancer cell line, through phage display biopanning with the help of bioinformatics. These results showed selective binding of the peptide (CTGNQAAFC) to SK-BR-3 rather than to normal breast cells and another breast cancer cell line. Bioinformatics tools predicted C5AR1 and CX3CR1 as potential biomarkers to which peptide Pep1 binds. Such peptide was found to be specific for SK-BR-3 cells and could be a valuable tool for the development of diagnostic probes as well as more specific targeted therapeutic solutions against this breast cancer subtype.

\section{ACKNOWLEDGMENTS}

This study was supported by the Portuguese Foundation for Science and Technology (FCT) under the scope of the strategic funding of UID/BIO/04469/2020 unit and BioTecNorte operation (NORTE-01-0145-FEDER-000004) funded by the European Regional Development Fund under the scope of Norte2020 - Programa Operacional Regional do Norte. Débora Ferreira and Ana Cláudia Pereira are recipient of fellowships supported by a doctoral advanced training (call NORTE-69-2015-15) funded by the European Social Fund under the scope of Norte2020 - Programa Operacional Regional do Norte. Cátia Santos-Pereira acknowledges the $\mathrm{PhD}$ fellowship PD/BD/128032/2016 funded by FCT under the scope of the doctoral programme in Applied and Environmental Microbiology (DP_AEM). The authors also acknowledge César Pimenta from NOVA Institute of Chemical and Biological Technology António Xavier (NOVA ITQB) for the docking insights.

\section{CONFLICTS OF INTEREST}

The authors declare no conflict of interest.

\section{AUTHOR CONTRIBUTIONS}

L.R.R. conceived and designed the experiments; D.F. and A.C.P. performed the experiments; S.F.S. designed and analyzed the docking assays; T.F.V. and C.S.P. performed and analyzed the docking assays; D.F., A.C.P., G.S., and L.R.R. analyzed and discussed the experimental data; L.R.R. contributed reagents/materials/analysis tools; D.F. and A.C.P. wrote the manuscript; S.F.S, G.S., and L.R.R. reviewed the manuscript.

\section{DATA AVAILABILITY STATEMENT}

Data available on request from the authors.

\section{ORCID}

Ana Cláudia Pereira (iD https://orcid. org/0000-0003-1727-8255

Débora Ferreira (DD https://orcid.org/0000-0002-0937-4047 Cátia Santos-Pereira (iD https://orcid.

org/0000-0002-0919-7618

Tatiana F. Vieira (D) https://orcid. org/0000-0001-5137-0798

Sérgio F. Sousa (D) https://orcid.org/0000-0002-6560-5284

Goreti Sales (D) https://orcid.org/0000-0001-9936-7336

Lígia R. Rodrigues (D) https://orcid.

org/0000-0001-9265-0630 


\section{REFERENCES}

Aghebati-Maleki, L., Bakhshinejad, B., Baradaran, B., Motallebnezhad, M., Aghebati-Maleki, A., Nickho, H., Yousefi, M., \& Majidi, J. (2016). Phage display as a promising approach for vaccine development. Journal of Biomedical Science, 23(1), 66. https://doi. org/10.1186/s12929-016-0285-9

Almendro, V., \& Fuster, G. (2011). Heterogeneity of breast cancer: Etiology and clinical relevance. Clinical and Translational Oncology, 13(11), 767-773. https://doi.org/10.1007/s1209 4-011-0731-9

American Cancer Society (2016). Breast cancer facts \& figures 2015 2016. American Cancer Society.

Bakhshinejad, B., Karimi, M., \& Khalaj-Kondori, M. (2015). Phage display: Development of nanocarriers for targeted drug delivery to the brain. Neural Regeneration Research, 10(6), 862-865. https://doi. org/10.4103/1673-5374.158330

Bar-Shavit, R., Maoz, M., Kancharla, A., Nag, J. K., Agranovich, D., Grisaru-Granovsky, S., \& Uziely, B. (2016). G Protein-coupled receptors in cancer. International Journal of Molecular Sciences, 17(8), https://doi.org/10.3390/ijms17081320

Bassi, M. T., Schiaffino, M. V., Renieri, A., Nigris, F. D., Galli, L., Bruttini, M., Gebbia, M., Bergen, A. A. B., Lewis, R. A., \& Ballabio, A. (1995). Cloning of the gene for ocular albinism type 1 from the distal short arm of the X chromosome. Nature Genetics, 10(1), 1319. https://doi.org/10.1038/ng0595-13

Bazan, J., Całkosiński, I., \& Gamian, A. (2012). Phage display-a powerful technique for immunotherapy: 1. Introduction and potential of therapeutic applications. Human Vaccines and Immunotherapeutics, 8(12), 1817-1828. https://doi.org/10.4161/ hv. 21703

Berman, H. M., Westbrook, J., Feng, Z., Gilliland, G., Bhat, T. N., Weissig, H., Shindyalov, I. N., \& Bourne, P. E. (2000). The protein data bank. Nucleic Acids Research, 28(1), 235-242. https://doi. org/10.1093/nar/28.1.235

Bienert, S., Waterhouse, A., de Beer, T. A., Tauriello, G., Studer, G., Bordoli, L., \& Schwede, T. (2017). The SWISS-MODEL Repository-new features and functionality. Nucleic Acids Research, 45(D1), D313-D319. https://doi.org/10.1093/nar/gkw1132

Boucher, J., Charalambous, M., Zarse, K., Mori, M. A., Kleinridders, A., Ristow, M., Ferguson-Smith, A. C., \& Kahn, C. R. (2014). Insulin and insulin-like growth factor 1 receptors are required for normal expression of imprinted genes. Proceedings of the National Academy of Sciences of the United States of America, 111(40), 14512-14517. https://doi.org/10.1073/pnas.1415475111

Erreni, M., Siddiqui, I., Marelli, G., Grizzi, F., Bianchi, P., Morone, D., Marchesi, F., Celesti, G., Pesce, S., Doni, A., Rumio, C., Roncalli, M. G., Laghi, L., Mantovani, A., \& Allavena, P. (2016). The fractalkine-receptor axis improves human colorectal cancer prognosis by limiting tumor metastatic dissemination. The Journal of Immunology, 196(2), 902-914. https://doi.org/10.4049/jimmu nol.1501335

Ferreira, D., Silva, A. P., Nobrega, F. L., Martins, I. M., Barbosa-Matos, C., Granja, S., Martins, S. F., Baltazar, F., \& Rodrigues, L. R. (2019). Rational identification of a colorectal cancer targeting peptide through phage display. Scientific Reports, 9(1), 3958. https:// doi.org/10.1038/s41598-019-40562-1

Frithiof, H., Welinder, C., Larsson, A. M., Rydén, L., \& Aaltonen, K. (2015). A novel method for downstream characterization of breast cancer circulating tumor cells following Cell Search isolation.
Journal of Translational Medicine, 13, 126. https://doi.org/10.1186/ s12967-015-0493-1

Gervasoni, S., Vistoli, G., Talarico, C., Manelfi, C., Beccari, A. R., Studer, G., Tauriello, G., Waterhouse, A. M., Schwede, T., \& Pedretti, A. (2020). A comprehensive mapping of the druggable cavities within the SARS-CoV-2 therapeutically relevant proteins by combining pocket and docking searches as implemented in pockets 2.0. International Journal of Molecular Sciences, 21(14), 5152. https://doi.org/10.3390/ijms21145152

Ghoncheh, M., Pournamdar, Z., \& Salehiniya, H. (2016). Incidence and mortality and epidemiology of breast cancer in the world. Asian Pacific Journal of Cancer Prevention, 17(S3), 43-46. https://doi. org/10.7314/APJCP.2016.17.S3.43

Gilbey, A. M., Burnett, D., Coleman, R. E., \& Holen, I. (2004). The detection of circulating breast cancer cells in blood. Journal of Clinical Pathology, 57(9), 903-911. https://doi.org/10.1136/ jcp.2003.013755

Giordano, R. J., Cardó-Vila, M., Lahdenranta, J., Pasqualini, R., \& Arap, W. (2001). Biopanning and rapid analysis of selective interactive ligands. Nature Medicine, 7(11), 1249-1253. https://doi.org/10.1038/ nm1101-1249

Hassan, A. M., \& El-Shenawee, M. (2011). Review of electromagnetic techniques for breast cancer detection. IEEE Reviews in Biomedical Engineering, 4, 103-118. https://doi.org/10.1109/ RBME.2011.2169780

Hauser, A. S., \& Windshügel, B. (2016). LEADS-PEP: A benchmark data set for assessment of peptide docking performance. Journal of Chemical Information and Modeling, 56(1), 188-200. https://doi. org/10.1021/acs.jcim.5b00234

Huang, J., Ru, B., Li, S., Lin, H., \& Guo, F. B. (2010). SAROTUP: Scanner and reporter of target-unrelated peptides. Journal of Biomedicine and Biotechnology, 2010, 101932. https://doi. org/10.1155/2010/101932

Imamura, T., Yamamoto-Ibusuki, M., Sueta, A., Kubo, T., Irie, A., Kikuchi, K., Kariu, T., \& Iwase, H. (2016). Influence of the C5aC5a receptor system on breast cancer progression and patient prognosis. Breast Cancer, 23(6), 876-885. https://doi.org/10.1007/ s12282-015-0654-3

Jones, G., Willett, P., Glen, R. C., Leach, A. R., \& Taylor, R. (1997). Development and validation of a genetic algorithm for flexible docking. Journal of Molecular Biology, 267(3), 727-748. https:// doi.org/10.1006/jmbi.1996.0897

Kruspe, S., Dickey, D. D., Urak, K. T., Blanco, G. N., Miller, M. J., Clark, K. C., Burghardt, E., Gutierrez, W. R., Phadke, S. D., Kamboj, S., Ginader, T., Smith, B. J., Grimm, S. K., Schappet, J., Ozer, H., Thomas, A., McNamara, J. O., Chan, C. H., \& Giangrande, P. H. (2017). Rapid and sensitive detection of breast cancer cells in patient blood with nuclease-activated probe technology. Molecular Therapy - Nucleic Acids, 8, 542-557. https://doi.org/10.1016/j. omtn.2017.08.004

Lappano, R., \& Maggiolini, M. (2012). GPCRs and cancer. Acta Pharmacologica Sinica, 33(3), 351-362. https://doi.org/10.1038/ aps.2011.183

Larimer, B. M., \& Deutscher, S. L. (2014). Development of a peptide by phage display for SPECT imaging of resistance-susceptible breast cancer. American Journal of Nuclear Medicine and Molecular Imaging, 4(5), 435-447.

Le Du, F., Ueno, N. T., \& Gonzalez-Angulo, A. M. (2013). Breast cancer biomarkers: Utility in clinical practice. Current Breast 
Cancer Reports, 5(4) , 284-292. https://doi.org/10.1007/s1260 9-013-0125-9

Le Guilloux, V., Schmidtke, P., \& Tuffery, P. (2009). Fpocket: An open source platform for ligand pocket detection. BMC Bioinformatics, 10, 168. https://doi.org/10.1186/1471-2105-10-168

Lee, D. K., George, S. R., Cheng, R., Nguyen, T., Liu, Y., Brown, M., Lynch, K. R., \& O'Dowd, B. F. (2001). Identification of four novel human $\mathrm{G}$ protein-coupled receptors expressed in the brain. Brain Research. Molecular Brain Research, 86(1-2), 13-22. https://doi org/10.1016/s0169-328x(00)00242-4

Lee, S. J., Depoortere, I., \& Hatt, H. (2019). Therapeutic potential of ectopic olfactory and taste receptors. Nature Reviews Drug Discovery, 18(2), 116-138. https://doi.org/10.1038/s41573-018-0002-3

Li, C., Gao, N., Xue, Q., Ma, N. I., Hu, Y., Zhang, J., Chen, B., \& Hou, Y. (2017). Screening and identification of a specific peptide binding to cervical cancer cells from a phage-displayed peptide library. Biotechnology Letters, 39(10), 1463-1469. https://doi.org/10.1007/ s10529-017-2381-7

Liu, F., Qi, C. L., Kong, M., Liu, T. T., Li, L., \& Li, B. J. (2016) Screening specific polypeptides of breast cancer stem cells from a phage display random peptide library. Oncology Letters, 12(6), 4727-4731. https://doi.org/10.3892/ol.2016.5248

Loeian, M. S., Mehdi Aghaei, S., Farhadi, F., Rai, V., Yang, H. W., Johnson, M. D., Aqil, F., Mandadi, M., Rai, S. N., \& Panchapakesan, B. (2019). Liquid biopsy using the nanotube-CTC-chip: Capture of invasive CTCs with high purity using preferential adherence in breast cancer patients. Lab on a Chip, 19(11), 1899-1915. https:// doi.org/10.1039/c9lc00274j

Mota, A. L., Evangelista, A. F., Macedo, T. O., Scapulatempo-Neto, C., Vieira, R. A., \& Marques, M. M. (2017). Molecular characterization of breast cancer cell lines by clinical immunohistochemical markers. Oncol Lett, 13, 4708-4712. https://doi.org/10.3892/ol.2017.6093

NEB:Ph.D.TM. Phage display libraries manual. In.

Nobrega, F. L., Ferreira, D., Martins, I. M., Suarez-Diez, M., Azeredo, J., Kluskens, L. D., \& Rodrigues, L. R. (2016). Screening and characterization of novel specific peptides targeting MDA-MB-231 claudin-low breast carcinoma by computer-aided phage display methodologies. BMC Cancer, 16(1), 881. https://doi.org/10.1186/ s12885-016-2937-2

O'Boyle, N. M., Banck, M., James, C. A., Morley, C., Vandermeersch, T., \& Hutchison, G. R. (2011). Open babel: An open chemical toolbox. Journal of Cheminformatics, 3, 33. https://doi. org/10.1186/1758-2946-3-33

Papa, V., Pezzino, V., Costantino, A., Belfiore, A., Giuffrida, D. Frittitta, L., Vannelli, G. B., Brand, R., Goldfine, I. D., \& Vigneri, R. (1990). Elevated insulin receptor content in human breast cancer. Journal of Clinical Investigation, 86(5), 1503-1510. https://doi. org/10.1172/JCI114868

Ranzani, M., Iyer, V., Ibarra-Soria, X., Del Castillo Velasco-Herrera, M., Garnett, M., Logan, D., \& Adams, D. J. (2017). Revisiting olfactory receptors as putative drivers of cancer. Wellcome Open Research, 2, 9. https://doi.org/10.12688/wellcomeopenres.10646.1

Rosenbaum, D. M., Rasmussen, S. G., \& Kobilka, B. K. (2009). The structure and function of G-protein-coupled receptors. Nature, 459(7245), 356-363. https://doi.org/10.1038/nature08144

Sauter, E. R. (2017). Reliable biomarkers to identify new and recurrent cancer. European Journal of Breast Health, 13(4), 162-167. https:// doi.org/10.5152/ejbh.2017.3635

Rouillard, A. D., Gundersen, G. W., Fernandez, N. F., Wang, Z., Monteiro, C. D., McDermott, M. G., \& Ma'ayan, A.(2016). The harmonizome: a collection of processed datasets gathered to serve and mine knowledge about genes and proteins. Database, 2016, 1-16. https://doi.org/10.1093/database/baw 100

Schiaffino, M. V., d'Addio, M., Alloni, A., Baschirotto, C., Valetti, C., Cortese, K., Puri, C., Bassi, M. T., Colla, C., De Luca, M., Tacchetti, C., \& Ballabio, A. (1999). Ocular albinism: Evidence for a defect in an intracellular signal transduction system. Nature Genetics, 23(1), 108-112. https://doi.org/10.1038/12715

Schmidtke, P., \& Barril, X. (2010). Understanding and predicting druggability. A high-throughput method for detection of drug binding sites. Journal of Medicinal Chemistry, 53(15), 5858-5867. https:// doi.org/10.1021/jm100574m

Schmidtke, P., Souaille, C., Estienne, F., Baurin, N., \& Kroemer, R. T. (2010). Large-scale comparison of four binding site detection algorithms. Journal of Chemical Information and Modeling, 50(12), 2191-2200. https://doi.org/10.1021/ci1000289

Shukla, G. S., \& Krag, D. N. (2005). Phage display selection for cell-specific ligands: Development of a screening procedure suitable for small tumor specimens. Journal of Drug Targeting, 13(1), 7-18. https://doi.org/10.1080/10611860400020464

Silva, V. L., Ferreira, D., Nobrega, F. L., Martins, I. M., Kluskens, L. D., \& Rodrigues, L. R. (2016). Selection of novel peptides homing the 4T1 CELL line: Exploring alternative targets for triple negative breast cancer. PLoS One, 11(8), e0161290. https://doi.org/10.1371/ journal.pone. 0161290

Singh, R. (2010). CX3CR1/CX3CL1 axis in breast cancer pathology and its therapeutic use. In S. K. Singh, M. K. Mishra, \& J. W. Lillard (Eds.). The Journal of Immunology, 204, 39-44.

Song, J. L., Chen, C., Yuan, J. P., \& Sun, S. R. (2016). Progress in the clinical detection of heterogeneity in breast cancer. Cancer Medicine, 5(12), 3475-3488. https://doi.org/10.1002/cam4.943

Sørensen, K. M., Meldgaard, T., Melchjorsen, C. J., Fridriksdottir, A. J., Pedersen, H., Petersen, O. W., \& Kristensen, P. (2017). Upregulation of Mrps18a in breast cancer identified by selecting phage antibody libraries on breast tissue sections. BMC Cancer, 17(1), 19. https:// doi.org/10.1186/s12885-016-2987-5

Sousa, S. F., Fernandes, P. A., \& Ramos, M. J. (2006). Protein-ligand docking: Current status and future challenges. Proteins, 65(1), 1526. https://doi.org/10.1002/prot.21082

Sousa, S. F., Ribeiro, A. J., Coimbra, J. T., Neves, R. P., Martins, S. A., Moorthy, N. S., Fernandes, P. A., \& Ramos, M. J. (2013). Proteinligand docking in the new millennium-a retrospective of 10 years in the field. Current Medicinal Chemistry, 20(18), 2296-2314. https:// doi.org/10.2174/0929867311320180002

Sriram, K., Moyung, K., Corriden, R., Carter, H., \& Insel, P. A. (2019). GPCRs show widespread differential mRNA expression and frequent mutation and copy number variation in solid tumors. PLoS Biology, 17(11), e3000434. https://doi.org/10.1371/journal.pbio.3000434

Studer, G., Rempfer, C., Waterhouse, A. M., Gumienny, R., Haas, J., \& Schwede, T. (2020). QMEANDisCo-distance constraints applied on model quality estimation. Bioinformatics, 36(8), 2647. https://doi. org/10.1093/bioinformatics/btaa058

Thun, M. J., DeLancey, J. O., Center, M. M., Jemal, A., \& Ward, E. M. (2010). The global burden of cancer: Priorities for prevention. Carcinogenesis, 31(1), 100-110. https://doi.org/10.1093/carcin/ bgp263

Trott, O., \& Olson, A. J. (2010). AutoDock Vina: Improving the speed and accuracy of docking with a new scoring function, efficient optimization, and multithreading. Journal of Computational Chemistry, 31(2), 455-461. https://doi.org/10.1002/jcc.21334 
Uhlen, M., Oksvold, P., Fagerberg, L., Lundberg, E., Jonasson, K., Forsberg, M., Zwahlen, M., Kampf, C., Wester, K., Hober, S., Wernerus, H., Björling, L., \& Ponten, F. (2010). Towards a knowledge-based Human Protein Atlas. Nature Biotechnology, 28(12), 1248-1250. https://doi.org/10.1038/nbt1210-1248

Umlauf, B. J., McGuire, M. J., \& Brown, K. C. (2015). Introduction of plasmid encoding for rare tRNAs reduces amplification bias in phage display biopanning. BioTechniques, 58(2), 81-84. https://doi. org/10.2144/000114256

Verdonk, M. L., Cole, J. C., Hartshorn, M. J., Murray, C. W., \& Taylor, R. D. (2003). Improved protein-ligand docking using GOLD. Proteins, 52(4), 609-623. https://doi.org/10.1002/prot.10465

Vieira, T. F., \& Sousa, S. F. (2019). Comparing AutoDock and vina in ligand/decoy discrimination for virtual screening. Applied Biosciences and Bioengineering, 9(21), 4538. https://doi.org/10.3390/app9214538

Vigneri, R., Goldfine, I. D., \& Frittitta, L. (2016). Insulin, insulin receptors, and cancer. Journal of Endocrinological Investigation, 39(12), 1365-1376. https://doi.org/10.1007/s40618-016-0508-7

Wang, H., Cai, J., Du, S., Guo, Z., Xin, B., Wang, J., Wei, W., \& Shen, X. (2017). Fractalkine/CX3CR1 induces apoptosis resistance and proliferation through the activation of the AKT/NF- $\mathrm{\kappa B}$ cascade in pancreatic cancer cells. Cell Biochemistry and Function, 35(6), 315-326. https://doi.org/10.1002/cbf.3278

Waterhouse, A., Bertoni, M., Bienert, S., Studer, G., Tauriello, G., Gumienny, R., Heer, F. T., de Beer, T. A. P., Rempfer, C., Bordoli, L., Lepore, R., \& Schwede, T. (2018). SWISS-MODEL: Homology modelling of protein structures and complexes. Nucleic Acids Research, 46(W1), W296-W303. https://doi.org/10.1093/nar/gky427
Weber, L., Maßberg, D., Becker, C., Altmüller, J., Ubrig, B., Bonatz, G., Wölk, G., Philippou, S., Tannapfel, A., Hatt, H., \& Gisselmann, G. (2018). Olfactory receptors as biomarkers in human breast carcinoma tissues. Frontiers in Oncology, 8, 33. https://doi.org/10.3389/ fonc.2018.00033

Wei, L. M., Cao, S., Yu, W. D., Liu, Y. L., \& Wang, J. T. (2015). Overexpression of CX3CR1 is associated with cellular metastasis, proliferation and survival in gastric cancer. Oncology Reports, 33(2), 615-624. https://doi.org/10.3892/or.2014.3645

Yuxuan, W. (2019). Important roles of C5a and C5aR in tumor development and cancer treatment. In (Vol. 136): E3S web of conferences, Les Ulis: EDP Sciences. https://doi.org/10.1051/e3sconf/20191 3606012

\section{SUPPORTING INFORMATION}

Additional supporting information may be found online in the Supporting Information section.

How to cite this article: Pereira AC, Ferreira D, Santos-Pereira C, et al. Selection of a new peptide homing SK-BR-3 breast cancer cells. Chem Biol Drug Des. 2021;97:893-903. https://doi.org/10.1111/ cbdd. 13816 